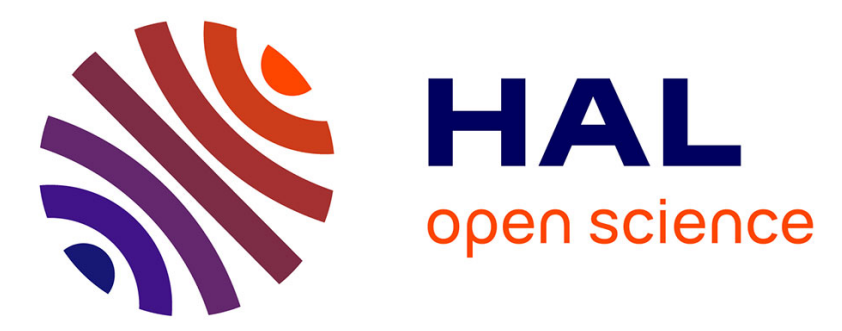

\title{
Diagnostic and prognostic value of MRI T2 quantification in heart transplant patients
}

Laurent Bonnemains, Thibaut Villemin, Jean-Marie Escanye, Gabriela Hossu, Freddy Odille, Fabrice Vanhuyse, Jacques Felblinger, Pierre-Yves Marie

\section{- To cite this version:}

Laurent Bonnemains, Thibaut Villemin, Jean-Marie Escanye, Gabriela Hossu, Freddy Odille, et al.. Diagnostic and prognostic value of MRI T2 quantification in heart transplant patients. Transplant International, 2014, 27 (1), pp.69-76. 10.1111/tri.12222 . hal-03227731

\section{HAL Id: hal-03227731 \\ https://hal.univ-lorraine.fr/hal-03227731}

Submitted on 20 May 2021

HAL is a multi-disciplinary open access archive for the deposit and dissemination of scientific research documents, whether they are published or not. The documents may come from teaching and research institutions in France or abroad, or from public or private research centers.
L'archive ouverte pluridisciplinaire HAL, est destinée au dépôt et à la diffusion de documents scientifiques de niveau recherche, publiés ou non, émanant des établissements d'enseignement et de recherche français ou étrangers, des laboratoires publics ou privés. 


\section{ESOT $202129^{\text {th }}$ August}

MN 1 $1^{\text {st }}$ September 2021

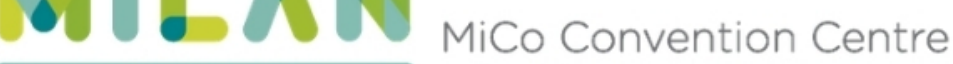

\section{PRE-CONGRESS WEBINARS}

The ESOT Congress 2021 features a series of pre-congress webinars, designed to foster constructive discussion and promote interaction in the run-up to the meeting. 


\title{
ORIGINAL ARTICLE
}

\section{Diagnostic and prognostic value of MRI T2 quantification in heart transplant patients}

\author{
Laurent Bonnemains, ${ }^{1,2,3}$ Thibaut Villemin, ${ }^{1}$ Jean-Marie Escanye, ${ }^{3,4}$ Gabriela Hossu, ${ }^{2,5}$ Freddy Odille, ${ }^{2,5}$ \\ Fabrice Vanhuyse, ${ }^{6}$ Jacques Felblinger ${ }^{2,3,5}$ and Pierre-Yves Marie ${ }^{3,4,7}$ \\ 1 Department of Cardiology, CHU Nancy, Nancy, France \\ 2 IADI, INSERM U947, Nancy, France \\ 3 University of Lorraine, Nancy, France \\ 4 Department of Medical Imaging, CHU Nancy, Nancy, France \\ 5 CIC-IT, CHU Nancy, Nancy, France \\ 6 Department of Cardio-Thoracic Surgery, CHU Nancy, Nancy, France \\ 7 INSERM U1161, Nancy, France
}

\section{Keywords}

heart graft rejection, MRI, prognostic,

T2 quantification.

\author{
Correspondence \\ Dr. Laurent Bonnemains, IADI, CHU Nancy \\ Brabois, rue du Morvan, F54511 \\ Vandoeuvre-les-Nancy, France. \\ Tel.: (33) 383 153241; \\ fax: (33) 383 154062; \\ e-mail: I.bonnemains@chu-nancy.fr
}

\section{Conflicts of interest}

There are no financial or other relations that could lead to a conflict of interest.

Received: 24 May 2013

Revision requested: 21 July 2013

Accepted: 20 October 2013

Published online: 18 November 2013

\section{Summary}

This study was designed retrospectively to assess the value of myocardial T2 to detect or predict ongoing acute heart rejection, in heart transplant patients, with a 1.5-T MRI magnet. One hundred and ninety-six myocardial T2 quantifications were performed on sixty consecutive heart transplant patients during routine follow-up. T2 values were assessed (i) with regard to the results of concomitant biopsies and (ii) with a Cox multivariate model for the prediction of subsequent rejections, defined by a $\geq$ grade 2 at biopsy or highly suspected in the absence of biopsy ( $>10 \%$ drop in ejection fraction with subsequent reversibility under treatment). T2 values were proposed as main covariate, after logit transformation and adjustment for other confounding parameters such as delay since graft surgery and delay before biopsy. T2 values were strongly linked (i) to the presence of rejection on concomitant biopsy $(P<0.0001)$ and (ii) to the risk of subsequent rejection on Cox multivariate model $(P<0.001)$. T2 values above $60 \mathrm{~ms}$ were associated with relative risk of rejection higher than 2.0 and rapidly increasing. In conclusion, myocardial T2 yields a high diagnostic and prognostic value for graft rejection in heart transplant patients.

doi:10.1111/tri.12222

\section{Introduction}

Cardiac transplantation offers improved quality of life and better survival for patients with advanced heart failure [1]. Nevertheless, this improvement is balanced by the risk of serious adverse events and especially of acute rejection during the first year $[2,3]$. Efficient monitoring of this risk is therefore mandatory to adapt immunosuppressive therapy. Clinical features of acute rejection are unreliable, with patients often remaining asymptomatic. Therefore, the gold standard for the diagnosis of acute cellular rejection is endomyocardial biopsy (EMB) [2-4]. This procedure is occasionally responsible for complications, however $[4,5]$, and there are conflicting data on both its variability and accuracy [6-8]. The EMB pathological classification proposed by the International Society for Heart and Lung Transplantation (ISHLT) has been modified in 2005, but still remains controversial $[8,9]$. According to Subherwal et al. [10], acute rejection with apparently normal EMB could occur in up to $20 \%$ of patients. Hence, there is a need for a noninvasive and more accurate identification of allograft rejection $[3,8,11-14]$. Eleven years ago, we presented a first study using myocardial T2 determination provided by a black-blood MRI sequence on a low-field $0.5 \mathrm{~T}$ magnet to detect acute heart transplant rejection [11]. This T2 determination was able to identify most of the acute rejections defined by the presence of damaged myocytes within EMB (grade $\geq 2$ ) and to predict the 
subsequent occurrence of acute rejection. Since this study, however, many changes have occurred in MRI technology and in transplanted patient care [15]. First, immunosuppressive treatments have markedly improved, leading to enhanced survival and to lowered risk of acute rejection $[16,17]$. Furthermore, acute rejections are now more silent and more difficult to detect [18]. Second, MRI technology has considerably changed with the diffusion of higher field magnets.

This study was therefore designed to assess the diagnostic and prognostic value of myocardial T2 quantification determined with a $1.5 \mathrm{~T}$ MRI magnet in currently monitored transplanted patients.

\section{Materials and methods}

This retrospective monocentric noninterventional study complies with the Declaration of Helsinki regarding medical research on human subjects and was approved by a local ethical committee.

\section{Population}

Sixty different and consecutive heart transplant patients benefited between January 2005 and April 2012 of a routine monitoring based on EMB and T2 quantification in MRI. Two hundred and twelve consecutive MRI examinations for heart graft monitoring were thus performed (on average: $3.5 \pm 5.0$ examinations per patient; maximum: 27). Two to four examinations per week could be dedicated to this indication. Therefore, patients were referred to MRI according to the magnet availability and to the likelihood of acute rejection (based on clinical or echographic signs and delay from transplantation).

Transvenous EMB was performed only as clinically indicated for systematic control or in cases of suspected rejection. The systematic controls were performed at the following rates: at 2-week intervals for the first 4 months following transplantation and then at monthly intervals until the end of the first year. Biopsies were obtained from the right side of the interventricular septum after the introduction of a dedicated catheter through the internal jugular vein. At least four specimens of right ventricular tissue were obtained with the same catheter. Biopsies were interpreted by two experienced pathologists, blinded to the $\mathrm{T} 2$ values, and graded according to ISHLT [9]: Grade 0 Revised $(0 \mathrm{R})=$ no evidence of rejection; Grade 1 Revised $(1 \mathrm{R})=$ mild rejection corresponding to Grades $1 \mathrm{~A}, 1 \mathrm{~B}$ and 2 of the 1990 ISHLT classification; Grade 2 Revised $(2 \mathrm{R})=$ moderate rejection corresponding to Grade $3 \mathrm{~A}$ of the 1990 classification; and Grade 3 Revised (3R) = severe rejection corresponding to Grades 3B and 4 of the 1990 classification.

\section{T2 quantifications}

Magnetic resonance imaging was conducted using a 1.5-T magnet (Signa Excite; GE Medical Systems, Milwaukee, WI, USA) and a body coil for transmission and reception of the MRI signal. The imaging protocol included localization sequences followed by the selection of a single mid-ventricular short axis slice for T2 measurement. Slice thickness was $10 \mathrm{~mm}$. This slice was acquired ten times with different effective echo times (TE) ranging evenly from 9 to $80 \mathrm{~ms}$. The sequence was a black-blood double-inversion fast-spin echo/turbo-spin echo, with an echo train length/ turbo factor of 16. The first inversion was nonselective and immediately followed by a selective slice inversion. The mean interecho time was $4.71 \mathrm{~ms}( \pm 0.30)$. The repetition time (TR) was equal to two heart beats. As TR was relatively short, complete recovery of longitudinal magnetization was not obtained. An inversion time of $485 \mathrm{~ms}$ was chosen to withdraw most of the blood-related signal [19]. The main acquisition parameters were as follows: field of view $42 \times 42 \mathrm{~cm}$, acquisition matrix $256 \times 192$, half Fourier space, and number of excitations equal to one. Images were obtained at the same phase of the cardiac cycle aiming for mid-diastole on sequential heart beats using prospective ECG gating. Each image was recorded during an endexpiratory breath-hold of no more than fifteen seconds.

All postprocessing computations were performed with a dedicated software developed with MATLAB (The Math Works Inc., Natick, MA, USA). At first, studies were anonymously submitted to one senior observer (JME) experienced in cardiac MRI and blinded to all patient data. Successive images obtained for each TE were corrected for heart displacement (translation and rotation) using an automatic feature-based image registration technique. The registration consisted in minimizing the distance between features extracted from each image by a Sobel edge detector using gradient descent optimization. The registration could be assessed by the observer through a movie presenting the ten images in a loop. When necessary, a manual correction of heart displacement was subsequently carried out. Thereafter, two regions of interest (ROI) were drawn by the observer covering the septum of one image and corresponding to the anteroseptal and inferoseptal segments according to AHA recommendations [20]. These two ROI were copied/pasted onto each image of the multiple TE series. Inferior, anterior, and lateral walls were not analyzed in this study, as previously described, to avoid the confusing influence of signal from surrounding fat [11]. An example of the positioning of these ROI is provided in Fig. 1a. T2 calculations were performed for each ROI with a nonlinear two-parameter Levenberg-Marquardt exponential fit applied to the myocardial signal measured on the echo images and based upon the equation 

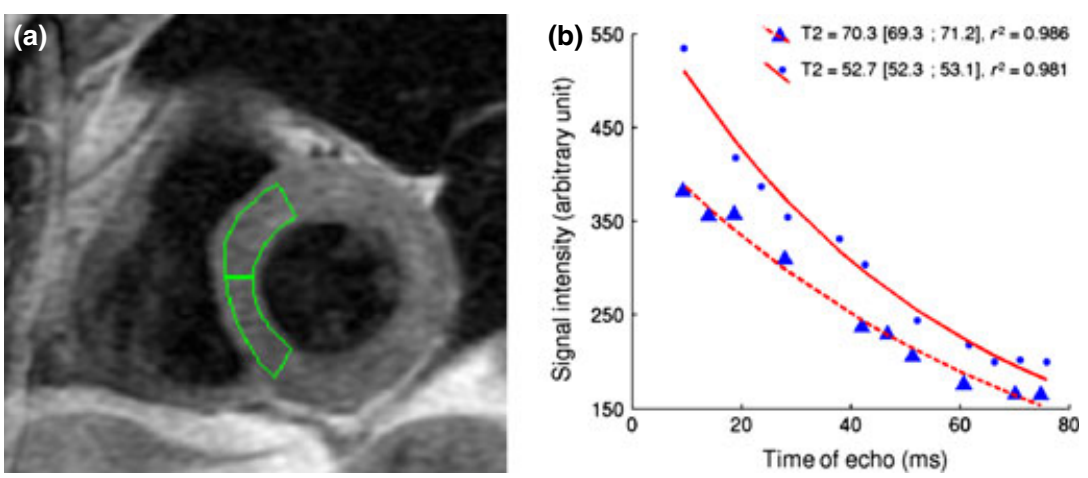

Figure 1 Illustration of our method to quantify myocardial T2. (a) Example of the positioning of the regions of interest for both septal segments. The physician chose to avoid the border of the myocardium to avoid error due to imperfect registration between the ten images. (b) Examples of exponential fits for normal and high T2. Both curves comprise 10 points corresponding to the signal intensity within a given septal regions of interest of images acquired with 10 different echo times (TE). Myocardium with higher T2 needs more time to decrease its signal intensity.

$M(\mathrm{TE})=M_{0} \times e^{-\frac{T E}{T 2}}$, TE being the specific effective echo time obtained during acquisition and $\mathrm{M}(\mathrm{TE})$ the myocardial signal. Examples of this fit are presented in Fig. $1 \mathrm{~b}$. Confidence intervals for T2 measurements and $r^{2}$ values were computed from the exponential fit. Segments with $r^{2}<0.97$ were discarded from the final analysis. When both septal segments were associated with $r^{2} \geq 0.97$, the mean of the two T2 values was used. This procedure was applied a second time by another experienced observer (LB) to assess interobserver reproducibility in a small subgroup, composed of the last thirty MRI examinations of the overall study.

\section{Prognostic value of myocardial T2}

To assess the predictive value of myocardial T2 measurements, patients were observed after each T2 quantification, and the time separating the examination from the nearest subsequent episode of significant rejection was collected. Observations were censored at the date of the last medical consultation or at the time of the next MRI T2 quantification. Observations were also censored whenever a rejection was related to an evident discontinuation of immunosuppressive treatment. Significant rejection was defined as follows: (i) acute rejection documented by the presence of damaged myocytes in EMB (former grade 2 plus grades $2 \mathrm{R}$ and $3 \mathrm{R}$ ) or (ii) marked decrease in left ventricle ejection fraction $(>10 \%)$, reversible after subsequent increase in immunosuppressive treatment, whenever EMB could not be performed because of technical difficulties for catheterization, or unstable clinical state.

\section{Statistics}

Descriptive data are reported as mean \pm standard deviation for continuous variables and proportion for qualitative variables. A Bland and Altman analysis [21] was performed within a subgroup of $30 \mathrm{MRI}$ examinations to assess T2 measurement reproducibility and compute interobserver $95 \%$ limits of agreement. The subgroup of T2 quantifications performed within $48 \mathrm{~h}$ of biopsy was analyzed (i) to compute the mean T2 value corresponding to grade $0 \mathrm{EMB}$ and (ii) to compare T2 and biopsy grades with nonparametric Kruskal-Wallis tests and (iii) with receiver operating characteristics (ROC) curves.

To explore the predictive value of T2 quantification, the relationship with subsequent significant rejection was assessed by multivariate Cox analysis. The covariates chosen for adjustment were delay since graft surgery (which obviously influences the instantaneous risk of graft rejection) and delay between MRI and biopsy. To cope with the influence of the patient (mandatory as several MRIs were performed for each patient), a mixed model was used. For the Cox analysis, T2 was encoded with a logit transformation because the influence of T2 measurements was expected not to comply with the implicit log-linearity hypothesis of the Cox model (i.e., proportionality between myocardial T2 and risk). The parameters of this logit transformation and the parameters of the mixed Cox model are detailed in Appendix 1. Instantaneous relative risk factor for T2 was deduced from the model.

All statistical analyses were performed using R 3.0.1 (R Foundation for Statistical Computing, Vienna, Austria) [22]. A $P<0.05$ was considered to be statistically significant.

\section{Results}

Population

Our population comprised 60 patients (47 men and 13 women). The main characteristics of the population are summarized in Table 1. Twenty-seven patients (four females and twenty-three males) presented one to three moderate-to-severe acute rejections documented by 
Table 1. Population characteristics with biopsy and MRI examination results.

\begin{tabular}{|c|c|}
\hline Population & $n=60$ \\
\hline Sex (Male, Female) & $M=47, F=13$ \\
\hline $\begin{array}{l}\text { Age at transplantation, } \\
\text { years (SD) }\end{array}$ & $\begin{array}{l}41 \text { years }(14.9) \min =14 \text { years, } \\
\max =67 \text { years }\end{array}$ \\
\hline Donor age, years $(S D)^{*}$ & $\begin{array}{l}36 \text { years }(12.3) \min =12 \text { years, } \\
\max =62 \text { years }\end{array}$ \\
\hline Body mass index, $\mathrm{kg} / \mathrm{m}^{2}$ (SD) & $23.7(4.2)$ \\
\hline Follow-up duration, years (SD) & 4.2 years $(2.3)$ \\
\hline Endomyocardial biopsies & $n=714$ \\
\hline grade $O R$ & $n=256$ \\
\hline grade $1 R$ & $n=406$ \\
\hline grade $2 \mathrm{R}$ & $n=47$ \\
\hline grade $3 R$ & $n=5$ \\
\hline Biopsies, per patient & $11.9(6.2)$ \\
\hline MRI examinations & $n=212$ \\
\hline Time from transplant to MRI & $\begin{array}{l}2 \text { years }(2.3) \min =13 \text { days, } \\
\max =12 \text { years }\end{array}$ \\
\hline T2 quantifications & $n=196$ \\
\hline $\mathrm{T} 2, \mathrm{~ms}(\mathrm{SD})$ & $60.7 \mathrm{~ms}(11)$ \\
\hline When EMB grade $O R(n=14)$ & $55.0 \mathrm{~ms}(2.3)$ \\
\hline When EMB grade $1 \mathrm{R}(n=42)$ & $64.1 \mathrm{~ms}(11)$ \\
\hline $\begin{array}{l}\text { When EMB grades } 2 \mathrm{R} \text { and } \\
3 \mathrm{R}(n=19)\end{array}$ & $72.1 \mathrm{~ms}(9)$ \\
\hline \multicolumn{2}{|c|}{ Time from $\mathrm{T} 2$ quantifications to $\mathrm{EMB}$, days } \\
\hline Whole population $(n=196)$ & Median $=40$ days \\
\hline When T2 $<55$ ms $(n=52)$ & Median=28 days \\
\hline $\begin{array}{l}\text { When } \mathrm{T} 2 \geq 55 \mathrm{~ms} \text { and } \leq 65 \\
\mathrm{~ms}(n=94)\end{array}$ & Median=77 days \\
\hline When $\mathrm{T} 2>65 \mathrm{~ms}(n=50)$ & Median=20 days \\
\hline
\end{tabular}

$\mathrm{EMB}$, endomyocardial biopsy.

*Data available for 50 donors only.

EMB (47 grade $2 \mathrm{R}$ and 5 grade $3 \mathrm{R}$ ), with $46 \%$ of the documented rejections occurring during the first year after transplantation.

\section{T2 quantifications}

Two hundred and twelve MRI examinations were performed. No adverse event was reported. Sixteen of these examinations were discarded for inadequate precision of T2 measurement (two exponential fits with $r^{2}$ under 0.97). Therefore, the final analysis incorporated the results of 196 T2 quantifications. Within this population, the mean T2 value was $60.7 \pm 11 \mathrm{~ms}$, and thresholds were $55 \mathrm{~ms}$ for the upper limit of the first quartile $\left(\mathrm{T} 2_{25 \%}\right)$ and $65 \mathrm{~ms}$ for the lower limit of the last quartile ( $\left.\mathrm{T} 2_{75 \%}\right)$. The $95 \%$ confidence interval of the $\mathrm{T} 2$ calculated within a given ROI had a raw width of $0.80 \pm 0.23 \mathrm{~ms}$. The interobserver $95 \%$ limits of agreement of the T2 measurements within a subset of 30 examinations were $2.4 \pm 0.37 \mathrm{~ms}$. Seventy-five myocardial T2 quantifications were performed within $48 \mathrm{~h}$ of a biopsy, and in this subgroup, (i) the confidence interval of the

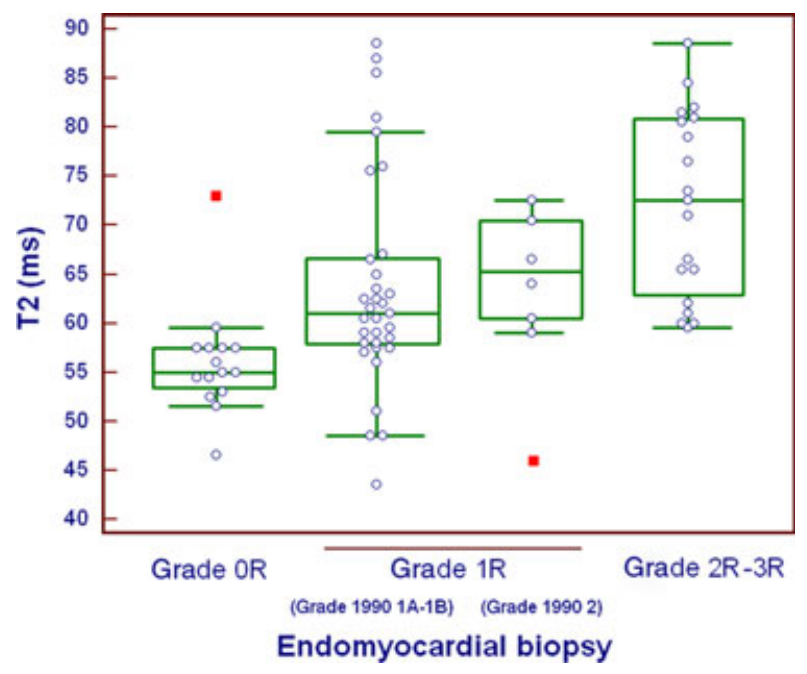

Figure 2 Box and whisker plots of $\mathrm{T} 2$ values according to the pathological grading of endomyocardial biopsies. The comparison was performed in a subset of patients when no more than $48 \mathrm{~h}$ of separate MRI and biopsy (75 cases). The dark squares correspond to outliers: the grade $O R$ one is a biopsy false negative (presence of many calcifications in the biopsy due to primary hyperoxaluria and reversible drop of ejection fraction: case number 8 in Table 2).

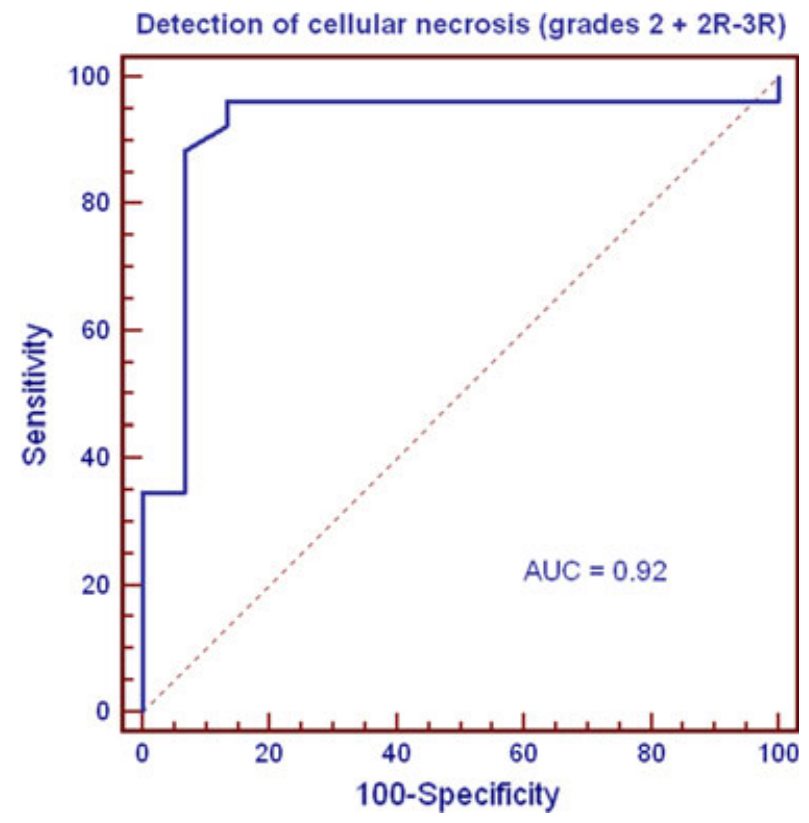

Figure 3 Receiving operator characteristics curve of $\mathrm{T} 2$ quantification used to separate normal biopsies (grade 0 ) from biopsies with damaged myocytes (former grade 2 plus grades 2R-3R).

myocardial T2 in the subset of patients with grade $0 \mathrm{EMB}$ was $55 \pm 2.3 \mathrm{~ms}$; (ii) there was a strong link $(P<0.0001)$ between T2 values and EMB as detailed in Fig. 2; and (iii) there was indeed a clear separation with no overlap between patients with grade 0 and those with grade $\geq 2$ at EMB, 
Table 2. Acute rejection diagnosed on a reversible alteration of ejection fraction.

\begin{tabular}{|c|c|c|c|c|c|c|c|}
\hline & \multicolumn{2}{|c|}{ Before rejection } & \multicolumn{3}{|c|}{ During rejection } & \multicolumn{2}{|l|}{ After rejection } \\
\hline & Clinic & $\mathrm{EF}(\%)$ & Clinic & $\mathrm{EF}(\%)$ & Treatment & Clinic & $\mathrm{EF}(\%)$ \\
\hline 1 & 1 & 55 & $\|$ & 35 & $\mathrm{Cb}$ & 1 & 55 \\
\hline 2 & 1 & 65 & III & 35 & $\mathrm{Cb}$ & II- & 55 \\
\hline 3 & I & 65 & $\|$ & 40 & $\operatorname{Aug}(C+T)$ & $\|$ & 55 \\
\hline 4 & I- & 60 & $11+$ & 40 & $\operatorname{Aug}(T)$ & $\|$ & 55 \\
\hline 5 & I & 60 & $\|$ & 45 & $\mathrm{Cb}$ & I & 60 \\
\hline 6 & 1 & 60 & $\|$ & 45 & $\mathrm{Cb}$ & 1 & 60 \\
\hline 7 & I & 60 & $\|$ & 35 & $\mathrm{Cb}$ & $\|$ & 50 \\
\hline 8 & I & 60 & III & 35 & $\mathrm{Cb}$ & I & 50 \\
\hline 9 & 1 & 60 & II+ & 40 & $\mathrm{Cb}$ & 1 & 60 \\
\hline 10 & I & 50 & III & 30 & $\mathrm{Cb}+\mathrm{Gb}$ & II, death 2 m & 50 \\
\hline 11 & 1 & 60 & I & 45 & $\operatorname{Aug}(C)$ & 1 & 60 \\
\hline 12 & I & 60 & $\|$ & 40 & $\mathrm{Sw}(\mathrm{Y}, \mathrm{TSR})+\mathrm{Cb}+\operatorname{aug}(\mathrm{M})$ & । & 50 \\
\hline 13 & I & 60 & $\|$ & 40 & $\mathrm{Cb}$ & । & 50 \\
\hline 14 & 1 & 50 & III & 25 & $\mathrm{Cb}$ & 1 & 50 \\
\hline 15 & I & 65 & $\|$ & 45 & $\mathrm{Cb}$ & ॥- & 50 \\
\hline 16 & 1 & 65 & III & 20 & $\mathrm{E}$ & $\|$ & 30 \\
\hline 17 & 1 & 60 & $\|$ & 30 & $\mathrm{Cb}$ & $\|$ & 45 \\
\hline 18 & $\|$ & 45 & $\|$ & 30 & $\mathrm{Cb}$ & 1 & 45 \\
\hline 19 & I & 60 & I & 30 & $\mathrm{Cb}$ & I & 50 \\
\hline 20 & 1 & 50 & $\|$ & 40 & $\mathrm{Cb}$ & I & 50 \\
\hline 21 & I & 65 & $\|$ & 45 & $\mathrm{Cb}$ & । & 55 \\
\hline
\end{tabular}

Treatment: $X b$, bolus of $X$; aug $(X)$, augmentation of $X ; \operatorname{sw}(X, Y)$, switch from $X$ to $Y$; $C$, corticoid; $T$, tacrolimus; TSR, tacrolimus sustained release; E, everolimus; Y, cyclosporine; $G$, antithymocyte globulin; $M$, mycophenolate.

Clinic : Roman figures represent NYHA class.

Table 3. Relative risk (RR) of ongoing rejection and delay before next rejection for different myocardial $\mathrm{T} 2$.

\begin{tabular}{llll}
\hline T2 $(\mathrm{ms})$ & RR & T2 $(\mathrm{ms})$ & $\begin{array}{l}\text { Delay before rejection* } \\
\text { Mean (Median) }\end{array}$ \\
\hline 55 & 1.0 & $<55$ & 102 days (28 days) \\
\hline 58.5 & 1.5 & & 24 days (6 days) \\
60 & 1.8 & $\geq 55$ and $\leq 65$ & \\
61 & 2.0 & & 11 days (0 days) \\
64 & 3.0 & & \\
\hline 68 & 4.0 & $>65$ & \\
75 & 5.0 & & \\
\hline
\end{tabular}

The relative risk of rejection remains low, for T2 below $60 \mathrm{~ms}$, but rapidly increases for higher T2 values.

*The observations without rejection were discarded for the computation.

grade 1 being mostly associated with intermediate T2 values. This separation between patients with grade 0 and those with grade $\geq 2$ at EMB is illustrated in Fig. 3 with an area under the ROC curve of 0.92 .

\section{Prognostic analysis}

Sixty-five episodes of significant rejections were identified after suppression of the censored events: 44 because of
Occurence of significant rejection after a T2 quantification

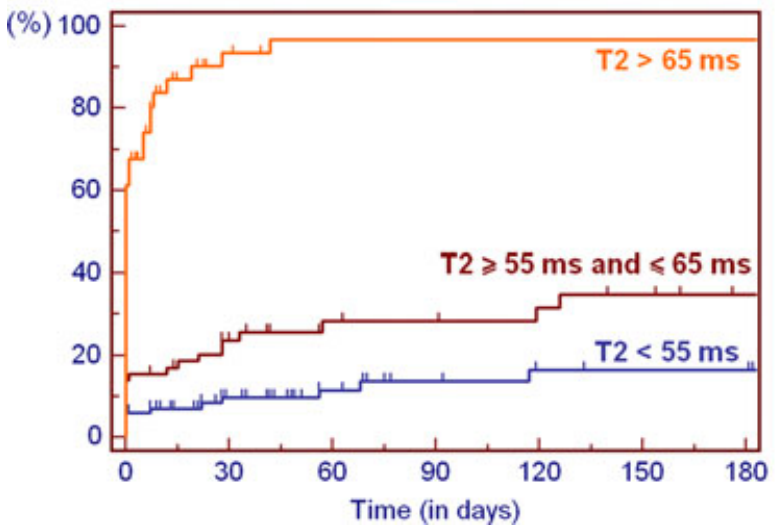

Figure 4 Prognostic value of T2 quantification during the follow-up of heart transplant patients: The three lines represent the prevalence of significant rejection in a given delay (in days) after a T2 quantification according to the measured T2 values: low T2 ( $<55$ ms: 52 examinations), intermediate T2 ( $\geq 55$ and $\leq 65$ ms: 94 examinations), and high T2 (>65 ms: 50 examinations). The observations of patients were censored at the next T2 quantification or rejection or major change of treatment. This categorical variable (low, intermediate, or high T2) was significant within the Cox model ( $P=0.04$ for intermediate, $P<0.0001$ for high T2).

EMB and 21 because of a reversible alteration of ejection fraction. These 21 cases are described in Table 2. The overall fit of the Cox model was excellent for predicting the 
occurrence of definite or highly probable acute rejection $(P<0.0001)$. After adjustment for the other covariates, there was a significant association between the risk of such rejection and T2 variations $(P=0.0007)$. The relative risks of rejection associated with different values of $\mathrm{T} 2$ above $55 \mathrm{~ms}$ are presented in Table 3. The relative risk for a T2 above $60 \mathrm{~ms}$ is 2.0 and raises to 4.0 above $65 \mathrm{~ms}$. To illustrate the influence of $\mathrm{T} 2$ value on event-free survival, survival curves were drawn (Fig. 4) for patients with low $(<55 \mathrm{~ms})$, medium $(\geq 55 \mathrm{~ms}$ and $\leq 65 \mathrm{~ms})$, and high ( $>65 \mathrm{~ms})$ T2. Low T2 values correspond to the first quartile of T2 values $(<25 \%)$, and high T2 values correspond to the fourth quartile of T2 values $(>75 \%)$.

\section{Discussion}

Heart transplant patients have to cope with the permanent threat of acute graft rejection [10]. This rejection may be life-threatening, and many discussions have been held to try to optimize the monitoring of these patients $[3,23,24]$. EMB remains the gold standard for diagnosis of cellular acute graft rejection, even though less invasive diagnostic methods such as MRI T2 quantification have been proposed $[3,11,24]$. Our method for T2 quantification was already published several years ago [11] and is mentioned in the "ISHLT Guidelines for the care of Heart Transplant Recipients" [24]. Hence, for the past several years, two to four MRI examinations per week have been dedicated to the monitoring of heart transplant patients in our institution, with a priority to patients with a higher likelihood of rejection. The present retrospective analysis of these MRI examinations gave evidence that myocardial T2 quantification still yielded high diagnostic and prognostic values in this population monitored with a modern 1.5-T MRI magnet in replacement of an older low-field system.

Indeed, in a first instance, our findings show that this technique provides robust results with a low rate of inconclusive examinations $(7.5 \%)$ along with a high interobserver reproducibility of the T2 measurements. Limits of agreement between the two observers were only of $2.4 \mathrm{~ms}$ and corresponded to less than $5 \%$ of the mean myocardial T2 values.

Second, the high diagnostic value of the T2 measurement could be confirmed in a subgroup where MRI had been performed within $48 \mathrm{~h}$ of EMB (see Fig. 2). In this subgroup, moderate-to-severe rejections ( $\geq$ grade $2 \mathrm{R}$ at EMB) were associated with high T2 values (mean $=72.5 \mathrm{~ms}$ ), whereas biopsies with no rejection (grade 0R) were associated with low $\mathrm{T} 2$ values ( mean $=55 \mathrm{~ms}$ ). By contrast, the mild forms of rejections (grade 1R) were associated with the whole range of $\mathrm{T} 2$ values, although the $1 \mathrm{R}$ biopsies showing damaged myocytes (former ISHLT grade 2) were associated with higher T2 values (mean $=65 \mathrm{~ms}$ ). This is in perfect accordance with our previous report [11] and justifies our choice to define rejection by the presence of damaged myocytes within the biopsy (former grade 2 plus grades $2 \mathrm{R}$ and $3 \mathrm{R}$ ) for the prognostic study.

Third, the high prognostic value of the T2 measurement could also be confirmed with regard to the risk of certain or highly probable rejection. This composite end point was used because, in clinical practice, several patients were treated for acute rejection, whereas EMB was not performed because it was not considered technically possible or safe (clinical instability). In twenty-one among our sixty-five cases of acute rejection treatment, this treatment was decided in the absence of EMB result. However, the high probability of acute rejection could be confirmed by clinical and echographic monitoring, as detailed in Table 2. The curves displayed in Fig. 4 indicate that the rate of definite or highly probable rejection during follow-up is dramatically higher in the group with high myocardial T2 (>65 ms) than in the remaining groups. However, there are several potential confounding factors in this analysis because of the retrospective nature of this study, as patients with a higher risk of rejection had a higher priority for referral to MRI and because the delay between EMB and MRI was variable, according to current recommendations and to the delay from transplantation. This is why a Cox analysis was conducted with multivariate adjustment to cope with these confounding factors. The variables proposed for adjustment were chosen from the literature and based on our experience. Variable dependence was verified using a univariate model before entering the said variables in multivariate analysis. To the best of our knowledge, this study is the first to study the prognostic value of myocardial T2 with adjustments in a multivariate model. We found a strong relationship between the relative risk of rejection and increase in T2 values. The relative risk of rejection remains low, for T2 below $60 \mathrm{~ms}$, but rapidly increases for higher T2 values.

Our findings constitute a strong argument in favor of a more extensive use of T2 quantification for risk stratification in the current monitoring of heart transplant patients. This could lead to recommending a decrease in the frequency of monitoring after a low T2 quantification, given the low probability of major event in this instance. However, this particular point should be confirmed prospectively in a multicentric and randomized study.

\section{Limitations}

Because this study was retrospective, the intervals between T2 measurements and EMB were variables, and no systematic T2 follow-up was conducted after treated rejections. 
The authors acknowledge the existence of emerging methods for T2 quantifications that were not available at the beginning of this study. We used a conventional blackblood spin-echo MRI sequence, which requires several breath-hold recordings for a single slice, whereas myocardial T2 may now be measured with only one breath-hold per slice. However, these T2 mapping methods are not available on every MRI scanner and are dependent on the manufacturer. Moreover, they are much more sensitive to various artifacts and especially to field and pulse inhomogeneities. Our procedure remains relatively short ( $\leq 15 \mathrm{~min}$ ) with the major advantage of being readily available, easy to perform, and highly robust. No specific dedicated cardiac coil or sequence is required, and only a conventional MRI scanner with an ECG-triggering system is needed.

\section{Conclusion}

Myocardial T2 measurements yield a high diagnostic and prognostic value for graft rejection in heart transplant patients. This simple MRI measurement could be very useful in the monitoring of these patients and could lead to a reduced need for EMB.

\section{Funding}

No grants were given for this study. No relation with industry to disclose.

\section{Authorship}

LB, TV, and PYM: wrote the manuscript. LB, TV, and JME: collected data. FO and JF: programmed the software. FV: managed the patients' follow-up. LB and GH: performed the statistical analysis. All authors contributed to the manuscript critical review.

\section{References}

1. Fisher DC, Lake KD, Reutzel TJ, Emery RW. Changes in health-related quality of life and depression in heart transplant recipients. J Heart Lung Transplant 1995; 14: 373.

2. White JA, Guiraudon C, Pflugfelder PW, Kostuk WJ. Routine surveillance myocardial biopsies are unnecessary beyond one year after heart transplantation. J Heart Lung Transplant 1995; 14: 1052.

3. Miller CA, Fildes JE, Ray SG, et al. Non-invasive approaches for the diagnosis of acute cardiac allograft rejection. Heart 2013; 99: 445.

4. Cooper LT, Baughman KL, Feldman AM, et al. The role of endomyocardial biopsy in the management of cardiovascular disease: a scientific statement from the American Heart Association, the American College of Cardiology, and the European Society of Cardiology Endorsed by the Heart Fail- ure Society of America and the Heart Failure Association of the European Society of Cardiology. Eur Heart J 2007; 28: 3076.

5. Baraldi-Junkins C, Levin HR, Kasper EK, Rayburn BK, Herskowitz A, Baughman KL. Complications of endomyocardial biopsy in heart transplant patients. J Heart Lung Transplant 1993; 12: 63.

6. Winters GL, McManus BM. Consistencies and controversies in the application of the International Society for Heart and Lung Transplantation working formulation for heart transplant biopsy specimens. Rapamycin Cardiac Rejection Treatment Trial Pathologists. J Heart Lung Transplant 1996; 15: 728 .

7. Marboe CC, Billingham M, Eisen H, et al. Nodular endocardial infiltrates (Quilty lesions) cause significant variability in diagnosis of ISHLT Grade 2 and $3 \mathrm{~A}$ rejection in cardiac allograft recipients. J Heart Lung Transplant 2005; 24: S219.

8. Taylor AJ, Vaddadi G, Pfluger H, et al. Diagnostic performance of multisequential cardiac magnetic resonance imaging in acute cardiac allograft rejection. Eur J Heart Fail 2010; 12: 45 .

9. Stewart S, Winters GL, Fishbein MC, et al. Revision of the 1990 working formulation for the standardization of nomenclature in the diagnosis of heart rejection. J Heart Lung Transplant 2005; 24: 1710.

10. Subherwal S, Kobashigawa JA, Cogert G, Patel J, Espejo M, Oeser B. Incidence of acute cellular rejection and non-cellular rejection in cardiac transplantation. Transplant Proc 2004; 36: 3171.

11. Marie PY, Angioï M, Carteaux JP, et al. Detection and prediction of acute heart transplant rejection with the myocardial T2 determination provided by a black-blood magnetic resonance imaging sequence. J Am Coll Cardiol 2001; 37: 825.

12. Butler CR, Thompson R, Haykowsky M, Toma M, Paterson I. Cardiovascular magnetic resonance in the diagnosis of acute heart transplant rejection: a review. J Cardiovasc Magn Reson 2009; 11: 7.

13. Almenar L, Igual B, Martínez-Dolz L, et al. Utility of cardiac magnetic resonance imaging for the diagnosis of heart transplant rejection. Transplant Proc 2003; 35: 1962.

14. Grasser B, Iberer F, Schaffellner S, et al. Non-invasive graft monitoring after heart transplantation: rationale to reduce the number of endomyocardial biopsies. Transpl Int 2000; 13(Suppl. 1): S225.

15. Kofler S, Bigdeli AK, Kaczmarek I, et al. Long-term outcomes after 1000 heart transplantations in six different eras of innovation in a single center. Transpl Int 2009; 22: 1140.

16. Everly MJ. Cardiac transplantation in the United States: an analysis of the UNOS registry. Clin Transpl 2008; 35: 43.

17. Fishbein MC, Kobashigawa J. Biopsy-negative cardiac transplant rejection: etiology, diagnosis, and therapy. Curr Opin Cardiol 2004; 19: 166.

18. Alonso-Pulpón L, Segovia J, Gómez-Bueno M, García-Pavía P. Heart transplantation: organisational aspects and current 
trends in immunosuppression-a view from Spain. Heart 2012; 98: 878.

19. Bernstein MA, King KF, Zhou XJ. Handbook of MRI Pulse Sequences. 1st edn. London: Elsevier, 2004: 654.

20. Cerqueira MD, Weissman NJ, Dilsizian V, et al. Standardized myocardial segmentation and nomenclature for tomographic imaging of the heart. A statement for healthcare professionals from the Cardiac Imaging Committee of the Council on Clinical Cardiology of the American Heart Association. Int J Cardiovasc Imaging 2002; 18: 539.

21. Bland JM, Altman DG. Statistical methods for assessing agreement between two methods of clinical measurement. Lancet 1986; 1: 307.

22. R Core Team. R: A Language and Environment for Statistical Computing. Vienna: R Foundation for Statistical Computing, 2013. URL http://www.R-project.org/.

23. Patel JK, Kobashigawa JA. Should we be doing routine biopsy after heart transplantation in a new era of anti-rejection? Curr Opin Cardiol 2006; 21: 127.

24. Costanzo MR, Dipchand A, Starling R, et al. The International Society of Heart and Lung Transplantation Guidelines for the care of heart transplant recipients. J Heart Lung

Transplant 2010; 29: 914.

\section{Appendix 1}

The logit transformation used the following function: $\operatorname{logit}(T 2)=\frac{e^{\left(T_{2}-M\right) / s}}{1+e^{\left(T_{2}-M\right) / s}}$ with $M$ being the value of T2 optimally separating patients with and without rejection and $S$ being a factor coding for the slope of the logit function. We chose $\mathrm{M}=60 \mathrm{~ms}$ from the results of the 75 couples MRI/ EMB performed simultaneously (Fig. 2). $S$ was chosen, among values equally distributed in a plausible interval (from 1 to $10 \mathrm{~ms}$ ), to optimize the Akaike information criterion (AIC) of the model. The best $S$ value was $4.0 \mathrm{~ms}$.

The proportional hazard assumption of the model was verified with the function " $\operatorname{cox} \cdot z \mathrm{ph}()$ ". The log-linearity assumption was verified by testing square and higher polynomials of each covariate. The mixed model version of the Cox analysis was adapted from the "coxme" R package and used in a stepwise manner with usual parameters (variable entered if $P<0.05$ and removed if $P>0.1$ ). 